\title{
The Impact of Climate Factors on the Prevalence of Urolithiasis in Northern Taiwan
}

\author{
Kuo-Jen Lin*, Po-Hung Lin*, Sheng-Hsien Chu, Hsiao-Wen Chen, Ta-Min Wang, Yang-Jen Chiang, \\ Kuan-Lin Liu, Hsu-Han Wang
}

Background: Urolithiasis is a common disease with high prevalence and recurrence. Its incidence varies in different geographic locations, and there are evidences that meteorological factors also affect urinary stone formation. The aim of this study is to analyze the effects of climate parameters on the numbers of shockwave treatments for urinary stones in our hospital, in order to understand the effects of these parameters on the prevalence of urolithiasis in northern Taiwan.

Methods: We retrospectively reviewed the records of extracorporeal shockwave lithotripsy (ESWL) performed in our hospital from December 2006 to November 2011. Repeated ESWL performed in the same patient within 1 month was excluded, and we only counted as one ESWL in our study. Climate data of the corresponding months were collected from Central Weather Bureau. The available monthly meteorological

\begin{abstract}
At a Glance Commentary
Scientific background of the subject

Urinary stone is a common disease with high recurrent rate. Geographic location affects the seasonal variation of urolithiasis. Reports have shown the effects of temperature, atmospheric pressure and sunshine on acute colic attacks.

\section{What this study adds to the field}

This study showed the ambient temperature is the most important climate factor affecting the prevalence of urolithiasis in northern Taiwan.
\end{abstract}

Results: $\quad$ Monthly ESWL number was positively correlated to temperature $(r=0.696)$, sunshine hours $(r=0.515)$, and wind speed $(r=0.369)$, while it was negatively correlated to humidity $(r=-0.441)$ and atmospheric pressure $(r=-0.568)$. Average monthly temperature had the strongest correlation to ESWL number $\left(r^{2}=0.484\right)$. Monthly rainfall and rain days were not significantly correlated to ESWL number. To investigate the climate parameters together, we introduced these correlated factors into the multivariate linear regression model which demonstrated only temperature $(\beta=1.438,95 \%$ CI: 3.703-9.144, $p<0.001)$ and atmospheric pressure $(B=0.803$, 95\% CI: $0.790-5.428, p=0.010$ ) to be independently related to monthly ESWL number.

Conclusion: Temperature and atmospheric pressure are associated with monthly ESWL number. Ambient temperature is the most important climate factor affecting the prevalence of urolithiasis in northern Taiwan. (Biomed J 2014;37:24-30)

Key words: atmospheric pressure, climate, extracorporeal shockwave lithotripsy, temperature, urolithiasis

U rolithiasis is a common disorder with lifetime prevalence of $7 \%$ in women and $12 \%$ in men in the USA and 3-4\% in women and 6-9\% in men in the other Western countries. ${ }^{[1,2]}$ Males are prone to urinary stone disease, with a male-to-female ratio about 2-3:1 according to a US survey. ${ }^{[1]}$ The recurrence rates after first colic episode are $10 \%$ within 1 year, $35 \%$ in 5 years, $40 \%$ by 5 years, and $75 \%$ at 20 years. ${ }^{[3,4]}$ As a result of the high prevalence

\footnotetext{
*K-J Lin and P-H Lin contributed equally to this article.

From the Department of Urology, Chang Gung Memorial Hospital at Linkou, Chang Gung University College of Medicine, Taoyuan, Taiwan

Received: Apr. 18, 2012; Accepted: Dec. 17, 2012

Correspondence to: Dr. Hsu-Han Wang, Department of Urology, Chang Gung Memorial Hospital at Linkou. 5, Fusing St., Gueishan, Taoyuan 333, Taiwan (R.O.C.). Tel: 886-3-3281200 ext. 2103; Fax: 886-3-3283529; E-mail: seanwang@ cgmh.org.tw
}

DOI: $10.4103 / 2319-4170.117888$ 
and recurrence, the treatment and work-time loss related to urolithiasis cost more than $\$ 5$ billion annually in the USA. $^{[5]}$ According to the 2010 annual report of National Health Insurance in Taiwan, 247,062 men and 129,335 women used healthcare with urolithiasis (ICD-9 codes 592 and 594) as the primary diagnosis and consumed 4.35 billion NT dollars or $0.86 \%$ of the healthcare budget. Therefore, understanding the epidemiology of urolithiasis is of crucial importance to reduce its attacks and related socioeconomic losses.

Geographic location affects the probability of forming urinary stones. The reported prevalence is 1-5\% in Asia, $5-9 \%$ in Europe, $13 \%$ in North America, and 20\% in Saudi Arabia. ${ }^{[6]}$ Regional differences are also noted within countries, with higher occurrence of urinary calculi in regions with increased average temperature ${ }^{[7,8]}$ and greater sunlight exposure. ${ }^{\left[{ }^{9]}\right.}$ Brikowski et al., estimated that the mean annual temperature accounts for $70 \%$ or more of the regional urolithiasis variability in the USA. ${ }^{[8]}$ Seasonal variation in urinary stone presentation is well described in the literature. The acute presentation of urolithiasis is associated with higher ambient temperature ${ }^{[10-17]}$ lower atmospheric pressure, ${ }^{[12,13]}$ and longer sunshine. ${ }^{[17]}$

We observed the trend of increased urolithiasis during summer time. The aim of this study is to investigate the seasonal variation of urolithiasis in our hospital and further determine which climate factor(s) may be associated with urinary calculi formation.

\section{METHODS}

\section{Patients}

We retrospectively reviewed the records of extracorporeal shockwave lithotripsy (ESWL) performed in our hospital from December 2006 to November 2011. Total number of ESWL procedures was recorded monthly during this 5-year period. Repeated ESWL of the same patient within 1 month was excluded. This study does not retrieve personal information of the patients, and hence, is exempt from evaluation of the institutional review board.

\section{Extracorporeal shockwave lithotripsy}

ESWL was performed with LiteMed LM-9200 ELMA lithotriptor (Lite-Med Inc., Taipei, Taiwan) on out-patient basis. Anesthesia was achieved with intravenous meperidine adjusted according to body weight. The patient remained clear conscious with continuous vital sign monitoring. Midazolam was added if the pain became intolerable. We used a crescendo energy ESWL program, starting with $16 \mathrm{keV}$ on the first 300 shock waves and ending with $18 \mathrm{keV}$ on the $2700^{\text {th }}-3000^{\text {th }}$ shock waves. Intermittent real-time fluoroscopic imaging was used to monitor stone location, which allows us to adjust the patient position, if necessary. After ESWL, patients stayed in the observation room for $1 \mathrm{~h}$ and we encouraged the patient to drink 2-3 L of water per day, if not contraindicated.

\section{Climate data}

Climate data of the corresponding months were collected from Central Weather Bureau. We used the data recorded in the nearest weather station, which is only $13 \mathrm{~km}$ away from our hospital, rather than the national average to match geographic facts. The available monthly meteorological data included highest, lowest, and average temperature (measured in degree Celsius), average relative humidity (recorded in percentage), total rainfall (measured in millimeters), total rain days (recorded in days), total sunshine hours (recorded in hours), average atmospheric pressure (measured in mBar, equivalent to $1 \mathrm{hPa}$ in SI unit), and maximum 10-min wind speed (measured in meters per second).

\section{Statistical analysis}

Correlations were used to check the association of each climate factor to total, male, and female monthly ESWL numbers. Univariate linear regressions of these correlations were applied to validate their linear relationship. Finally, we applied all these correlated factors into a multivariate linear regression model to examine which factor(s) affected the monthly ESWL number independently. The data were analyzed using SPSS, version 19, statistical software (IBM Corporation, Armonk, NY, USA). All tests were two-tailed with statistical significance set at $p<0.05$.

\section{RESULTS}

\section{Monthly variations}

ESWL and meteorological data are summarized according to the corresponding month in Table 1. Average monthly ESWL number was the lowest in February (73.8/month), increasing gradually and reaching the highest in July (135.0/month), and then declined steadily by February. Males constituted the majority (65.8-75.2\%) of the ESWL patients as the incidence of urolithiasis is higher in men. The average monthly temperature showed a similar pattern to the monthly ESWL number, with the lowest $\left(15.82^{\circ} \mathrm{C}\right)$ in January and highest $\left(29.58^{\circ} \mathrm{C}\right)$ in July. The variations of highest monthly temperature $\left(26.00^{\circ} \mathrm{C}-37.52^{\circ} \mathrm{C}\right)$, lowest monthly temperature $\left(7.04^{\circ} \mathrm{C}-24.02^{\circ} \mathrm{C}\right)$, and monthly sunshine hours (81.64-219.80 h) are also parallel to the monthly ESWL numbers. On the contrary, average monthly atmospheric pressure was the highest (1020.74 mBar) in January and lowest (1004.60 mBar) in August, while there was no 
Table 1: Average ESWL and meteorological factors according to month recorded

\begin{tabular}{|c|c|c|c|c|c|c|c|c|c|c|c|}
\hline \multirow[t]{2}{*}{ Month } & \multicolumn{3}{|c|}{ Average ESWL data } & \multicolumn{3}{|c|}{ Temperature $\left({ }^{\circ} \mathrm{C}\right)$} & \multirow{2}{*}{$\begin{array}{c}\text { Humidity } \\
(\%)\end{array}$} & \multirow{2}{*}{$\begin{array}{l}\text { Rainfall } \\
(\mathrm{mm})\end{array}$} & \multirow{2}{*}{$\begin{array}{l}\text { Pressure* } \\
\text { (mBar) }\end{array}$} & \multirow{2}{*}{$\begin{array}{c}\operatorname{Sun}^{\dagger} \\
\text { (h) }\end{array}$} & \multirow{2}{*}{$\begin{array}{l}\text { Wind } \\
(\mathrm{m} / \mathrm{sec})\end{array}$} \\
\hline & Average ESWL & Male (\%) & Female $(\%)$ & Average & High & Low & & & & & \\
\hline Jan & 85.4 & $64.2(75.2)$ & $21.2(24.8)$ & 15.82 & 26.00 & 7.04 & 77.40 & 89.88 & 1020.74 & 81.64 & 7.56 \\
\hline Feb & 73.8 & $54.0(73.2)$ & $19.8(26.8)$ & 17.16 & 29.20 & 9.66 & 78.80 & 119.96 & 1016.98 & 88.70 & 7.06 \\
\hline March & 102.6 & $69.0(67.3)$ & $33.6(32.7)$ & 18.46 & 31.22 & 10.00 & 76.20 & 164.10 & 1016.18 & 104.40 & 8.18 \\
\hline April & 101.0 & $70.8(70.1)$ & $30.2(29.9)$ & 21.26 & 32.92 & 12.92 & 74.80 & 120.42 & 1013.24 & 101.54 & 7.84 \\
\hline May & 111.8 & $80.4(71.9)$ & $31.4(28.1)$ & 25.14 & 35.16 & 16.70 & 73.00 & 169.06 & 1008.66 & 160.62 & 7.42 \\
\hline June & 109.8 & $79.8(72.7)$ & $30.0(27.3)$ & 27.44 & 35.90 & 21.10 & 77.40 & 436.46 & 1005.74 & 136.08 & 7.50 \\
\hline July & 135.0 & $97.6(72.3)$ & $37.4(27.7)$ & 29.58 & 37.52 & 24.02 & 72.20 & 159.32 & 1005.06 & 219.80 & 8.58 \\
\hline Aug & 128.0 & $92.6(72.3)$ & $35.4(27.7)$ & 29.24 & 36.74 & 23.98 & 73.00 & 297.70 & 1004.60 & 200.24 & 9.38 \\
\hline Sept & 127.4 & $88.4(69.4)$ & $39.0(30.6)$ & 28.02 & 35.24 & 22.68 & 72.00 & 331.74 & 1006.84 & 188.74 & 10.24 \\
\hline Oct & 125.8 & $82.8(65.8)$ & $43.0(34.2)$ & 24.54 & 33.00 & 18.62 & 74.40 & 181.32 & 1012.72 & 96.40 & 8.42 \\
\hline Nov & 113.0 & $77.4(68.5)$ & $35.6(31.5)$ & 21.38 & 31.18 & 14.16 & 75.60 & 152.80 & 1016.52 & 89.44 & 7.62 \\
\hline Dec & 109.6 & $80.0(73.0)$ & $29.6(27.0)$ & 17.78 & 28.50 & 9.82 & 74.20 & 79.30 & 1018.42 & 117.82 & 6.66 \\
\hline
\end{tabular}

Abbreviations: ESWL: Extracorporeal shockwave lithotripsy; *: Average atmospheric pressure; ${ }^{\dagger}$ : Monthly sunshine; ${ }^{*}$ : Maximum 10 -min wind speed recorded

obvious seasonal association in monthly humidity, rainfall, and wind speed with the ESWL numbers.

When we plot the monthly ESWL numbers with meteorological parameters in the continuous 5-year time period, as shown in Figure 1, the association between seasonal variations and ESWL can be demonstrated more clearly. The ESWL number was parallel to temperatures [Figure 1A-C] and sunshine hours [Figure 1G], while it showed the opposite trend with atmospheric pressure [Figure $1 \mathrm{~F}]$. The relationships between ESWL number and the remaining parameters are not so apparent.

\section{Correlations}

In order to understand the association between ESWL and climate better, we examined the correlations between them. As shown in Figure 2 and Table 2, the monthly ESWL number was positively correlated to temperature $(r=0.696, p<0.001)$, sunshine hours $(r=0.515$, $p<0.001)$, and wind speed $(r=0.369, p=0.004)$, while it was negatively correlated to humidity $(r=-0.441$, $p<0.001)$ and atmospheric pressure $(r=-0.568$, $p<0.001)$. Average monthly temperature had the strongest correlation to ESWL number, with an $r^{2}$ value of 0.484 . Monthly rainfall and monthly rain days were not significantly correlated to ESWL number.

\section{Linear regressions}

The line of fit, which was generated by univariate linear regression, was plotted on each of the scatter plots in Figure 2. These lines further verified the linear relationship between the factor examined and the monthly ESWL number. Average temperature $(\beta=3.110, p<0.001)$, humidity $(B=-2.869, p<0.001)$, atmospheric pressure $(\beta=-2.196, p<0.001)$, sunshine hours $(\beta=0.202$,
Table 2: Correlations of monthly climate factors to ESWL performed in the month

\begin{tabular}{|c|c|c|c|c|c|c|}
\hline & \multicolumn{2}{|c|}{ Male ESWL } & \multicolumn{2}{|c|}{ Female ESWL } & \multicolumn{2}{|c|}{ Total ESWL } \\
\hline & $r$ & $p$ & $r$ & $p$ & $r$ & $p$ \\
\hline Average temperature & 0.671 & $<0.001^{\dagger}$ & 0.496 & $<0.001^{\dagger}$ & 0.696 & $<0.001^{\dagger}$ \\
\hline Highest temperature & 0.522 & $<0.001^{\dagger}$ & 0.439 & $<0.001^{\dagger}$ & 0.563 & $<0.001^{\dagger}$ \\
\hline Lowest temperature & 0.666 & $<0.001^{\dagger}$ & 0.507 & $<0.001^{\dagger}$ & 0.697 & $<0.001^{\dagger}$ \\
\hline Relative humidity & -0.466 & $<0.001^{\dagger}$ & -0.240 & 0.065 & -0.441 & $<0.001^{\dagger}$ \\
\hline Monthly rainfall & 0.167 & 0.202 & 0.311 & $0.016^{*}$ & 0.248 & 0.056 \\
\hline Monthly rain days & -0.238 & 0.067 & -0.017 & 0.898 & -0.183 & 0.162 \\
\hline Monthly sun hours & 0.575 & $<0.001^{\dagger}$ & 0.222 & 0.089 & 0.515 & $<0.001^{\dagger}$ \\
\hline Atmospheric pressure & -0.561 & $<0.001^{\dagger}$ & -0.379 & $0.003^{\dagger}$ & -0.568 & $<0.001^{\dagger}$ \\
\hline Ten-minute wind speed & 0.290 & $0.025^{*}$ & 0.384 & $0.002^{\dagger}$ & 0.369 & $0.004^{\dagger}$ \\
\hline
\end{tabular}

Abbreviations: ESWL: Extracorporeal shockwave lithotripsy;

$r$ : Pearson correlation, ${ }^{*} p<0.05 ;{ }^{\dagger} p<0.01$

$p<0.001)$, and wind speed $(\beta=5.361, p=0.004)$ had significant linear relationship to monthly ESWL number. To investigate the climate parameters together, we introduced these correlated factors into the multivariate linear regression model to eliminate the possible interactions. Table 3 demonstrates that only temperature $(\beta=1.438$, 95\% CI: 3.703-9.144, $p<0.001)$ and atmospheric pressure $(B=0.803,95 \% \mathrm{CI}: 0.790-5.428, p=0.010)$ were independently related to monthly ESWL number. The roles of humidity, sunshine hours, and wind speed were no longer significant in the multivariate model.

\section{DISCUSSION}

\section{Patients}

Among the 6616 ESWLs we recorded, 4685 (70.81\%) were in males and 1931 (29.19\%) were in females. The male-to-female ratio after adjusting population was 2.47 , which is similar to Soucie et al.'s report (M:F $=1.98)$ of 

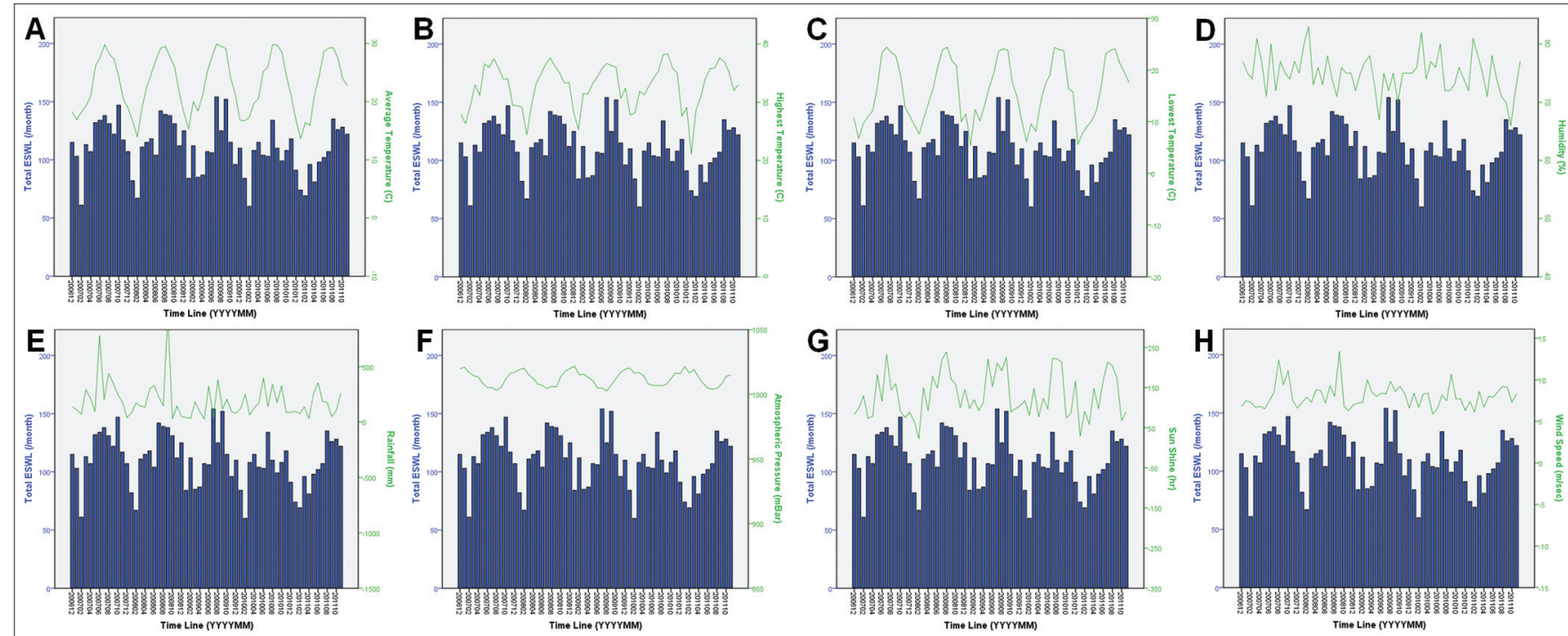

Figure 1: Five-year monthly ESWL number (blue bar) and climate parameter (green line) trends. A: average temperature, B: highest temperature, C: lowest temperature, D: humidity, E: rainfall, F: atmospheric pressure, G: sun shine, H: wind speed.
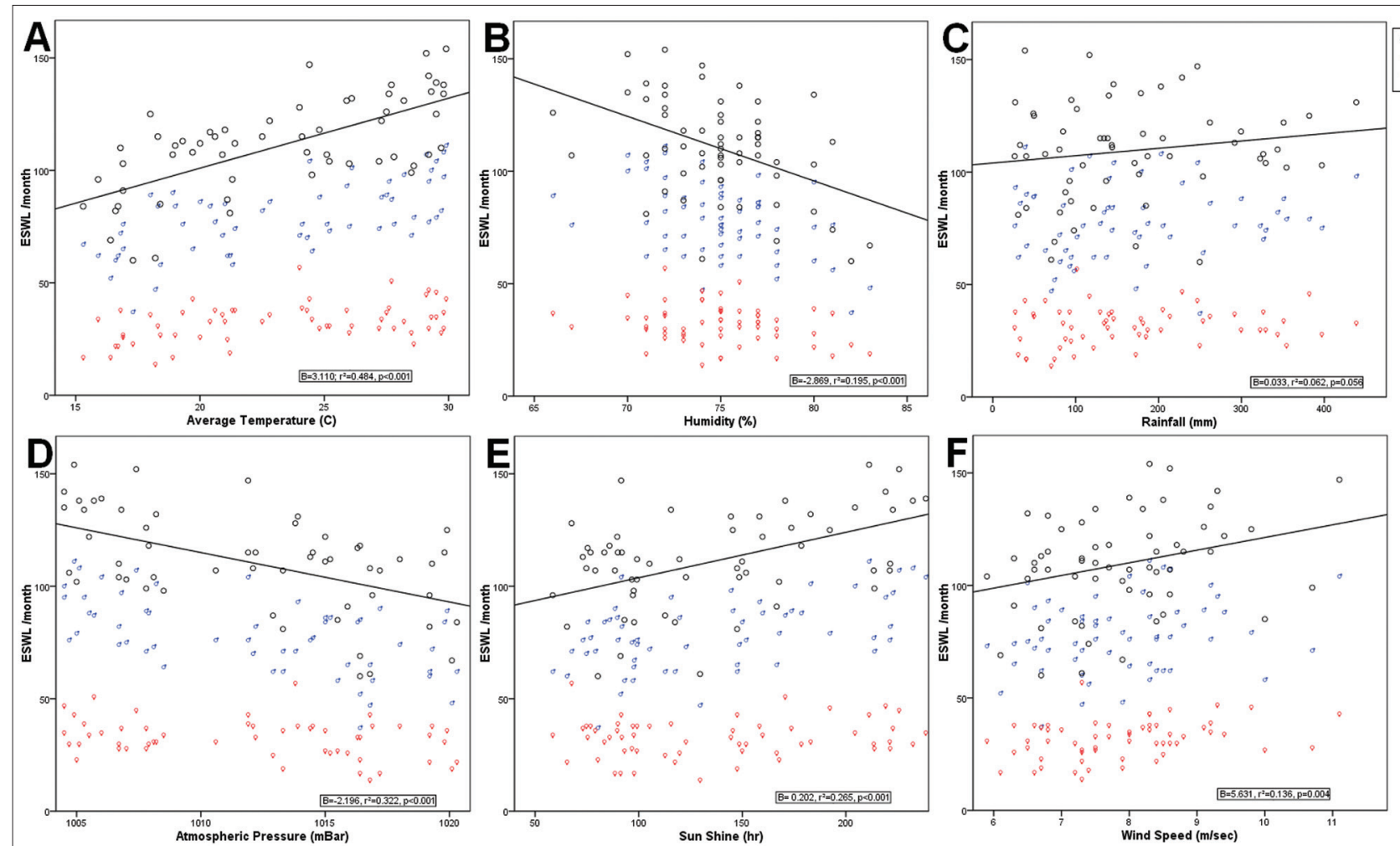

Figure 2: Climate versus ESWL scatter plot. A: average temperature, B: humidity, C: rainfall, D:atmospheric pressure, E: sun shine, F: wind speed.

the USA based on the questionnaire in the Second Cancer Prevention Survey (CPS II) ${ }^{[7]}$ The ratio was higher (3.17) in a previous Taiwanese population-based study, which was based on emergency visits with urinary stone as the principle diagnosis in National Health Insurance database. They only excluded the re-admissions to emergency department within 7 days after ESWL; hence, the possibility of repeat- ed counts and uncertain use of urolithiasis ICD-9 codes is still present in such study based on insurance database. This can be demonstrated when we examine the 2010 National Health Insurance report, the urolithiasis (ICD-9 codes 592 and 594) male-to-female ratio in emergency visits is higher than the ratio in non-emergency visits (2.61 in emergency vs. 1.75 in in-patient and out-patient clinics). 
Table 3: Multivariate linear regression of correlated climate factors to monthly ESWL

\begin{tabular}{lcccc}
\hline & $\begin{array}{c}\text { Standardized } \\
\text { coefficient Beta }\end{array}$ & \multicolumn{2}{c}{$\begin{array}{c}\text { 95\% confidence } \\
\text { interval of Beta }\end{array}$} & \\
\cline { 3 - 4 } & & Lower & Upper & \\
\hline Temperature & 1.438 & 3.703 & 9.144 & $<0.001^{\dagger}$ \\
Humidity & -0.121 & -2.612 & 1.033 & 0.389 \\
Sun hours & -0.127 & -0.191 & 0.091 & 0.480 \\
Atm. pressure & 0.803 & 0.790 & 5.428 & $0.010^{*}$ \\
Wind speed & 0.138 & -0.900 & 5.117 & 0.166 \\
\hline
\end{tabular}

Abbreviations: ESWL: Extracorporeal shockwave lithotripsy;

Atm: Atmospheric, ${ }^{*} p<0.05 ;{ }^{\dagger} p<0.01$

\section{Temperature and urolithiasis}

Several studies showed increasing urolithiasis incidence with higher ambient temperature in the Middle East, ${ }^{[13,15]}$ Europe, ${ }^{[10,11,18-21]}$ Australia and New Zealand, ${ }^{[17,22]}$ Japan, ${ }^{[12,23]}$ and the USA. ${ }^{[14]}$ The hypothesized mechanism for higher temperatures causing stone disease is attributed to heat-induced sweating, leading to reduced urine volume and increased urinary concentrations. When urinary concentration exceeds its solubility, the supersaturation state allows the crystal to nucleate and grow, promoting stone formation. The British study in 246 male stone formers showed statistically significant changes from the minimum value of both 24-h urine calcium and oxalate concentrations in the winter, with maximum values in the summer ${ }^{[10]} \mathrm{A}$ later Finnish study also echoed this finding with unchanged serum calcium levels. ${ }^{[24]}$

Our records showed parallel curves between monthly ESWL number and correlated monthly temperatures [Figure 1A-C]. The correlations between the average, highest, and lowest monthly temperatures and the total monthly ESWL numbers are strong [Table 2], and the same was observed with both gender subgroups as well, compatible with most literature reports. This can be confirmed by the linear regression; as shown in Figure 2A, the average monthly temperature has significant positive linear relationship not only to total monthly ESWL number (black circles; $\beta=3.110, r^{2}=0.484, p<0.001$; shown as black line) but also to male subgroup (marked in blue; $\beta=2.221, r^{2}=0.451$, $p<0.001$; line not shown) and female subgroup (marked in red; $\beta=0.889, r^{2}=0.246, p<0.001$; line not shown). It suggests that for each $1{ }^{\circ} \mathrm{C}$ rise in average monthly temperature, ESWL number may increase 2.221 /month in males and $0.889 /$ month in females. The results in highest and lowest monthly temperature are comparable (data not shown). When Fakheri and Goldfarb plotted the renal stone prevalence rate to correlated temperature data from the CPS II study, ${ }^{[25]}$ they showed similar trends that temperature rise has stronger influence on renal stone prevalence in males $\left(B=0.08, r^{2}=0.37\right.$, $p<0.05)$ than in females $\left(B=0.02, r^{2}=0.51, p<0.05\right)$. They speculated that men are more likely to have occupa- tions exposing them to environmental temperature. Further analysis on patients' occupation or working environment may be needed to support this theory.

\section{Humidity and urolithiasis}

Our data showed monthly average relative humidity has inverse correlation to total and male monthly ESWL numbers but not to female monthly ESWL number [Table 2]. Using linear regression, we can predict that for every rise of $1 \%$ relative humidity, total and male monthly ESWL number will decrease by 2.869 and 2.243 , respectively. No significant linear pattern can be found between humidity and female monthly ESWL number. However, when we put humidity into the multivariate lineal model [Table 3], it is observed that it no longer affects monthly ESWL number independently. Formiconi and Tagliaferri showed inverse linear relationship on monthly ureter colics and humidity in their 10-year study in Florence. ${ }^{[18]}$ Another Italian 1-year series showed negative correlation and inverse linear regression in humidity and renal colics. ${ }^{[19]}$ The later group did mention that the correlation is strongest when minimum monthly relative humidity 15 days prior to stone attack was used. However, they did not show multivariate regression result in their reports.

The hypothesis supporting dry climate increases urinary stone formation is mainly depending on dehydration. Although Taiwan and Italy are mostly surrounded by sea, the climate pattern is different. The average monthly relative humidity in our study ranged from $66 \%$ to $83 \%$ with a mean of $74.92 \pm 0.44 \%$ and the humidity of 37 out of the 60 months was above $75 \%$, while in the Italian report the median humidity ranged from $60 \%$ to $84 \%$ and the mean was $69.83 \pm 2.26 \%$, with more continental influence in their climate as their minimum humidity may drop to $34.9 \%$ in February. Perhaps the relative lower humidity in summer months in our study ( $72 \%$ in July compared to $78.8 \%$ in February) [Table 1] enhances dehydration and increases the chance of stone formation slightly. But the limited variation of humidity in Taiwan may be the reason that temperature overwhelms humidity in multivariate linear regression model.

\section{Atmospheric pressure and urolithiasis}

Figure 1F demonstrates opposed curves obtained between monthly ESWL number and average monthly atmospheric pressure during our study. Inverse correlations and negative linear relationship were also observed [Figure 2D], as well as in each gender subgroup. Linear regression showed that increase of every $1 \mathrm{mBar}$ in average monthly atmospheric pressure may decrease 1.609 ESWL/month in male $\left(r^{2}=0.315, p<0.001\right)$ and $0.588 \mathrm{ESWL} /$ month in female $\left(r^{2}=0.143, p=0.003\right)$. Fijita reported that falling 
barometric pressure was associated with higher incidence of urinary stone colics in Japan. ${ }^{[12,23]}$ A 3-year study in Saudi Arabia also presented negative correlations between atmospheric pressure and monthly colic attacks. ${ }^{[13]}$ This trend can be explained by dehydration in the low atmospheric pressure environment, as frequently observed in the high-altitude mountainous area. Hale et al., established that the insensible skin water loss is inversely dependent on barometric pressure in their small pilot study. ${ }^{[26]}$ However, their study was based on extreme barometric condition (lowest to $253 \mathrm{mmHg}$ ) which is seldom experienced in normal human habitant area.

Interestingly, when we put average monthly atmospheric pressure into the multivariate linear model [Table 3] predicting total monthly ESWL number, it remained significant, but the inverse trend was converted to positive ( $\beta=0.803$, 95\% CI: $0.790-5.428, p=0.01)$. When we focused on men only, atmospheric pressure was no longer significant ( $\beta=0.628,95 \%$ CI: $-0.050-3.652, p=0.056$ ). On the contrary, it remained significant in women $(B=0.539,95 \%$ CI: $0.228-2.388, p=0.019)$. This inconsistency cannot be well explained; therefore, we examined the collinearity between temperature and atmospheric pressure. The collinearity tolerance is 0.106 which suggests pretty strong collinear relationship between these two parameters. As a result, it is too risky to conclude atmospheric pressure has independent influence on stone formation according to our data.

\section{Sunshine, wind speed, and urolithiasis}

Figure $1 \mathrm{G}$ shows a similar relation of monthly sunshine hours to total ESWL number. Correlations demonstrate that sunshine is positively related to total and male ESWL number, but not in females; linear regression also supports this. For each increase of $1 \mathrm{~h}$ of sunshine in a month, total and male ESWL number was increased by $0.202\left(r^{2}=0.265\right.$, $p<0.001)$ and $0.167\left(r^{2}=0.167, p<0.001\right)$, respectively, while no significant linear relationship was noted in females ( $\beta=0.035, r=0.049, p=0.089)$. Sunshine was reported to be positively correlated to stone incidence. ${ }^{[11,17,27]}$ A possible explanation besides the direct relationship to sunlight exposure to ambient temperature is that sunshine activates vitamin D and therefore increases serum 25-hydroxyvitamin $\mathrm{D}$, and urinary calcium is increased in summer. ${ }^{[24]}$ Our gender inconsistence may be explained by men working outdoors more frequently than women, due to which men have more exposure to sunlight and steeper effect of increased sunshine in the issue to urinary stone. When we put sunshine into the multivariate linear regression model, it does not affect monthly ESWL number independently. Lo et al., showed in their study in Auckland that acute colic attacks vary significantly with hours of sunshine in their 9-year multivariate analysis. ${ }^{[17]}$
Our results showed significant correlations between wind speed and monthly total, male, and female ESWL numbers [Table 2], as well positive linear relationships $(\beta=5.631,3.282$, and 2.350, respectively; and all $p<0.05)$. Wind is associated with dehydration, as observed in an experiment on cyclists in a laboratory environment of different wind speeds. ${ }^{[28]}$ The study revealed that insensible water loss is greater in these participants cycling under higher wind speed. However, the wind in natural environment is very unsteady and the meteorological record has its limits interpreting the ever-changing air flow in our surroundings. When we examine wind speed in the multivariate model, it is observed that it no longer affects the monthly ESWL number. To the best of our knowledge, there is no definite conclusion about the association between wind and urolithiasis in the literature.

\section{Limitations}

This study was based on the meteorological data obtained from Central Weather Bureau, using the corresponding climate records from a single station near our hospital. Although most patients who seek medical care at our hospital live within $100 \mathrm{~km}$ range, few of them may live further away and the meteorological data obtained may not really represent the environment where these patients reside. Upon acceptance of the Institutional Review Board to retrieve the personal data of these patients, we may record their age, address, work, medical history, and family history in order to further analyze the relationship between weather and urinary stones in detail. This will give us a better understanding of the impact of climate on urolithiasis. By doing so, we may establish an estimation model to educate people to take action to prevent urolithiasis according to the climate changes in different seasons and, therefore, to reduce urolithiasis attacks or recurrences.

\section{Conclusions}

Meteorological factors do affect the numbers of monthly ESWL numbers in northern Taiwan. Although many factors do influence ESWL numbers in linear regressions, only temperature and atmospheric pressure remain the independent risk factors in our study. This gives us a better understanding on why the attack rates of urolithiasis are higher in summer months. Further expansion of this climate-urolithiasis model may enable us to give tailor-made recommendations to urolithiasis patients to prevent the related socioeconomic loss.

\section{REFERENCES}

1. Pearle MS, Calhoun EA, Curhan GC. Urologic diseases in America project: Urolithiasis. J Urol 2005;173:848-57. 
2. Hughes P. Kidney stones epidemiology. Nephrol 2007;12:26-30.

3. Wikinson $\mathrm{H}$. Clinical investigation and management of patients with renal stones. Ann Clin Biochem 2001;38:180-7.

4. Worcester EM, Coe FL. Calcium kidney stones. N Eng J Med 2010;363:954-63.

5. Saigal CS, Joyce G, Timilsina AR. Direct and indirect costs of nephrolithiasis in an employed population: Opportunity for disease management? Kidney Int 2005;68:1808-14.

6. Ramello A, Vitale C, Marangella M. Epidemiology of nephrolithiasis today. J Nephrol 2000;13:S45-S50.

7. Soucie JM, Thun M, Coates RJ, McClellan W, Austin H. Demographic and geographic variability of kidney stones in the United States. Kidney Int 1994;46:893-9.

8. Brikowski T, Lotan Y, Pearle M. Climate related increase in the prevalence of urolithiasis in the United States. Proc Natl Acad Sci USA 2008;105:9841-6.

9. Parry E, Lister I. Sunlight and hypercalciuria. Lancet 1975;305:1063-5.

10. Robertson W, Peacock M, Marshall R, Speed R, Nordin B. Seasonal variations in the composition of urine in relation to calcium stone-formation. Clin Sci Mol Med 1975;49:597-602.

11. Barker DJ, Donnan SP. Regional variations in the incidence of upper urinary tract stones in England and Wales. Br Med J 1978;1:67-70.

12. Fujita K. Epidemiology of urinary stone colic. Eur Urol 1979;5:26-8.

13. Al Hadramy MS. Seasonal variation of urinary stone colic in Arabia. J Pak Med Assoc 1997;47:281-4.

14. Chauhan V, Eskin B, Allegra JR, Conchrane DG. Effect of season, age, and gender on renal colic incidence. Am J Emerg Med 2004;22:560-3.

15. Barsi A, Moghaddam SM, Khoddam R, Nejad ST, Hakimi A. Monthly variations of urinary stone colic in Iran and its relationship to the fasting month of Ramadan. J Pak Med Assoc 2004;54:6-8.

16. Chen YK, Lin HC, Chen CS, Yeh SD. Seasonal variations in urinary calculi attacks and their association with climate: A population-based study. J Urol 2008;179:564-9.
17. Lo SS, Johnston R, Al Sameraaii A, Metcalf PA, Rice ML, Masters JG. Seasonal variation in the acute presentation of urinary calculi over 8 years in Auckland, New Zealand. BJU Int 2009;106:96-101.

18. Formiconi G, Tagliagerri G. Weather and the incidence of urinary stone colics in the Province of Florence. Int J Biometeor 1984;84:147-56.

19. Boscolo-Berto R, Dal Moro F, Abate A, Arandjelovic G, Tosato F, Bassi PF. Do weather conditions influence the onset of renal colic? a novel approach to analysis. Urol Int 2008;80:19-25.

20. Cupisti A, Pasquali E, Lusso S, Carlino F, Orsitto E, Melandri R. Renal colic in Pisa emergency department: Epidemiology, diagnostics and treatment patterns. Intern Emerg Med 2008;3:241-4.

21. Cervellin G, Comelli I, Comelli D, Cortellini P, Lippi G, MEschi T, et al. Regional short-term climate variations influence on the number of visits for renal colic in a large urban emergency department: Result of a 7-year survey. Intern Emerg Med 2011;6:141-7.

22. Baker P, Coyle P, Bais R, Rofe A. Influence of season, age and sex on renal stone formation in South Australia. Med J Aust 1993;159:390-2

23. Fijita K. Weather and the incidence of urinary stone colic in Tokyo. Int J Biometeor 1987;31:141-6.

24. Elomaa I, Karonen SL, Kariento AL, Pelkonen R. Seasonal variation of urinary calcium and oxalate excretion, serum $25(\mathrm{OH}) \mathrm{D} 3$ and albumin level in relation to renal stone formation. Scand J Uro Nephrol 1982;16:155-61.

25. Fakheri RJ, Goldfarb DS. Ambient temperature as a contributor to kidney stone formation: Implications of global warming. Kidney Int 2011;79:1178-85.

26. Hale FC, Westland RA, Taylor CL. Barometric and vapour pressure influences on insensible water loss. J Appl Physiol 1958;12:20-8.

27. Safarinejad MR. Adult urolithiasis in a population-based study in Iran: Prevalence, incidence, and associated risk factors. Urol Res 2007;35:73-82

28. Saunders AG, Dugas JP, Tucker R, Lambert MI, Noakes TD. The effects of different air velocities on heat storage and body temperature in humans cycling in a hot humid climate. Acta Physiol Scand 2005;183:241-55. 